\title{
Atherosclerotic plaque locations may be related to different ischemic lesion patterns
}

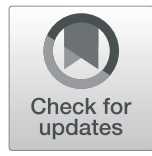

\author{
Ho Geol Woo', Sung Hyuk Heo', Eui Jong Kim², Dae-il Chang ${ }^{1}$, Tae Jin Song ${ }^{3}$ and Bum Joon Kim ${ }^{4 *}$ (D)
}

\begin{abstract}
Background: Atherosclerosis of the internal carotid artery (ICA) is an important cause of ischemic stroke. Artery-toartery embolism is the major stroke mechanism in patients with atherosclerotic carotid disease. This study hypothesized that the atherosclerotic ICA geometry and plaque location would be associated with lesion pattern in patients with acute ischemic stroke.

Methods: Ischemic stroke patients with symptomatic proximal ICA disease (> 50\% diameter stenosis) were enrolled. The carotid plaque location was divided into high-apical and low-body types. The geometric parameters of the ICA (angles between arteries) were measured, and ischemic lesion patterns were classified according to the number, location, and size of the lesions. Factors associated with plaque location and lesion pattern, dichotomized by size, were investigated.

Results: Of the 93 acute ischemic stroke patients enrolled, 31 had high-apical and 62 had low-body plaques. Hyperlipidemia was more prevalent and the common carotid artery (CCA)-ICA angle was wider (167.7 $\pm 10.4^{\circ}$ vs $162.3 \pm$ $\left.9.8^{\circ}, p=0.019\right)$ in patients with low-body than high-apical plaques. Low-body plaques were more frequently associated with small scattered or cortical lesions ( $54.8 \%$ vs. $32.3 \%, p=0.040$ ), whereas high-apical plaques were more frequently associated with large lesions having additional lesions (38.7\% vs. $11.3 \%, p=0.002)$. The presence of low-body plaques (odds ratio: $3.106,95 \%$ confidence interval: $1.105-8.728, p=0.032$ ) was independently associated with the small lesiononly pattern.
\end{abstract}

Conclusions: Low-body plaques are more frequently associated with small scattered lesions, whereas high-apical plaques are more frequently associated with large lesions having additional lesions. A wide CCA-ICA angle is associated with lowbody plaque of the carotid artery.

Keywords: Atherosclerosis, Ischemic stroke, Hemodynamics

\section{Background}

Atherosclerosis of the carotid artery is one of the major causes of ischemic stroke, with artery-to-artery embolism being the major stroke mechanism in patients with atherosclerosis of the carotid artery [1]. Thromboembolism due to rupture of ulcerative plaque as well as the degree of stenosis has been especially associated with ischemic stroke in these patients [2,3]. These risk factors, however, have not been associated with the distribution

\footnotetext{
* Correspondence: medicj80@hanmail.net

${ }^{4}$ Department of Neurology, Asan Medical Center, University of Ulsan, Song-Pa, PO Box 145, Seoul 138-600, South Korea

Full list of author information is available at the end of the article
}

and size of these ischemic lesions. Blood flow may be an important factor affecting lesion size and pattern because it can influence the activation of platelets and the coagulation cascade and dislodge thrombi $[4,5]$.

Although atherosclerotic plaque of the carotid artery is associated with old age, male sex, and hyperlipidemia [1], these risk factors have not been associated with specific plaque locations in the carotid artery among individual patients. In addition to these general risk factors, hemodynamics may also affect the location of plaque within the carotid artery. For example, high wall shear stress (WSS) is associated with plaque formation at the apex of the carotid artery and low WSS with plaque

C The Author(s). 2020 Open Access This article is licensed under a Creative Commons Attribution 4.0 International License, which permits use, sharing, adaptation, distribution and reproduction in any medium or format, as long as you give appropriate credit to the original author(s) and the source, provide a link to the Creative Commons licence, and indicate if changes were made. The images or other third party material in this article are included in the article's Creative Commons licence, unless indicated otherwise in a credit line to the material. If material is not included in the article's Creative Commons licence and your intended use is not permitted by statutory regulation or exceeds the permitted use, you will need to obtain permission directly from the copyright holder. To view a copy of this licence, visit http://creativecommons.org/licenses/by/4.0/ The Creative Commons Public Domain Dedication waiver (http://creativecommons.org/publicdomain/zero/1.0/) applies to the data made available in this article, unless otherwise stated in a credit line to the data. 
formation at the bulb of the carotid artery [6, 7]. Moreover, the geometric properties of the carotid artery (i.e., bifurcation angle and radius), which are thought to regulate WSS, have been associated with plaque location in the carotid artery $[8,9]$. Specifically, the nature and sizes of emboli from atherosclerotic stenotic lesions may depend on plaque location affecting the WSS inside the carotid artery. The present study therefore investigated the association of lesion patterns of acute ischemic stroke, as shown by diffusion-weighted imaging (DWI), with the location of carotid plaques.

\section{Methods}

\section{Subjects}

This study was a retrospective analysis of a prospectively collected database of acute ischemic stroke patients (within 7 days from stroke onset) between January 2013 and December 2017. Patients classified by the Trial of Org 10,172 in Acute Stroke Treatment (TOAST) as having large artery atherosclerosis with symptomatic proximal internal carotid artery (pICA) disease were enrolled [10]. Significant stenosis of the pICA was defined as > $50 \%$ diameter reduction to near-occlusion (artery beyond the stenosis has collapsed, but has remaining patency). Symptomatic pICA disease was considered present when significant stenosis of the pICA was the likely cause of index middle cerebral artery (MCA) or anterior cerebral artery (ACA) infarction [11, 12].

Patients were excluded if they had (1) embolic sources from the heart (e.g., atrial fibrillation or valvular heart disease) or the aorta, (2) other uncommon etiologies such as dissection or moyamoya disease, (3) tandem stenotic lesions at the intracranial ICA and MCA or ACA, or (4) results on contrast enhanced magnetic resonance angiography (MRA) that did not allow assessment of geometric properties (e.g., complete occlusion or poor MRA quality). The study protocol was approved by the institutional review board of Kyung Hee University Hospital, which waived the need for informed consent because of its retrospective nature.

\section{Clinical data and neuroimaging}

Demographic characteristics, vascular risk factors, concurrent medications, and baseline laboratory results were obtained from the prospectively acquired stroke database. Hyperlipidemia was defined by patient having past history of hyperlipidemia, using a lipid-lowering agent including statins or patient diagnosed hyperlipidemia at admission for LDL-cholesterol levels [13].

On the day of admission, all patients underwent magnetic resonance imaging and MRA in the following sequence: DWI, fluid attenuated inversion recovery imaging, gradient echo imaging, T1- and T2-weighted imaging, and intracranial and extracranial contrast enhanced MRA.
The patterns of infarction on DWI were classified according to the number, location, and maximum diameter of lesions $[14,15]$. Lesions were classified as single or multiple, and as large $(\geq 15 \mathrm{~mm})$ or small $(<15 \mathrm{~mm})$ based on their maximum diameter. Single lesions were further classified as cortical (small), subcortical (small or large), or cortico-subcortical (large). Multiple lesions were classified as small scattered lesions or a large lesion with additional lesions. The topography of ischemic lesions according to vascular territory was determined with reference to published templates [16]. For further analysis, lesion pattern was dichotomized according to the presence or absence of a large lesion. Lesion location was divided in to cortical, subcortical and corticosubcortical lesions.

\section{Carotid plaque and geometry}

The presence and location of plaques and the degree of stenosis in the pICA were assessed on contrast enhanced MRA. Atherosclerotic plaques of the carotid artery were classified as being high-apical or low-body plaques. High-apical plaques were defined as plaques in the transitional zone of the bulb and the proximal cervical ICA segment, with or without the involvement of the body segment. Low-body plaques were defined as those in the transitional zone of the common carotid artery (CCA) and the bulb, and are located mainly in the lower body segment, with or without the involvement of the apical segment (Supplementary Figure S1). To differentiate among type of enlarged plaques, the location of the main plaque component and the level of the most severe stenosis were considered [7]. Two independent researchers evaluated the type of plaque and dichotomized the location to high-apical or low-body type. If any discrepancy exists, a consensus meeting was held to finalize the type of atherosclerosis, with more than three researchers and considering all the imaging modalities available.

The geometry of the carotid artery was quantitatively analyzed by a modification of previous methods [17]. The ICA-external carotid artery (ECA) angle was defined as the angle between the projections of the ICA0-ICA5 and ECA0-ECA5 vectors onto the bifurcation plane (Supplementary Figure S1). The CCA-ICA and CCAECA angles were defined similarly. Moreover, ICA planarity was defined as the angle between the out-of-plane components of the CCA and ICA vectors. The ICA-toCCA diameter ratio was calculated as the ICA5 diameter divided by the CCA5 diameter.

Geometric factors that could affect the risk of embolism or vulnerability of plaque were also evaluated. These factors included 1) the degree of stenosis measured by North American Symptomatic Carotid Endarterectomy Trial (NASCET) criteria; 2) the presence of ulcer, defined as a niche in the plaque surface $>2 \mathrm{~mm}$ in depth 
on contrast enhanced extracranial MRA [18]; 3) carotid webs, defined as thin intraluminal filling defects along the posterior wall of the carotid bulb in oblique sagittal reformatted image on contrast enhanced extracranial MRA [19]; and 4) ICA kinking, defined as an extreme form of tortuous ICA with angulation of the vessel's axis $\leq 90^{\circ}[20]$.

\section{Statistical methods}

Demographic characteristics, vascular risk factors, concurrent medications, laboratory findings, geometrical factors, and ischemic lesion patterns were compared in patients grouped by plaque location. Pearson chi-square tests, independent $t$-tests, and Mann-Whitney U-tests were used as appropriate. In addition, clinical and imaging characteristics were compared according to different lesion patterns and location on DWI. Multivariable binary logistic regression analysis was performed to investigate the independent association between lesion patterns (small lesions only vs. large lesion) and the type of plaque and the geometric properties of the carotid bifurcation. Odds ratios (ORs) were calculated, along with 95\% confidence intervals (95\% CIs). A $p$ value $<0.05$ was considered statistically significant. All statistical analyses were performed using SPSS 22.0 for Windows (IBM Corp. Armonk, NY, USA).

\section{Results}

Of the 3061 patients with acute ischemic stroke between January 2013 and December 2017, 657 (21.5\%) were classified as having large artery atherosclerosis according to the TOAST classification. Among the latter, 117 (17.8\%) patients had symptomatic pICA disease. After excluding patients with complete occlusion of the carotid artery, those with no DWI or MRA data, and those with poor MRA quality, the final study population included 93 patients.

The 93 patients included $75(80.6 \%)$ men and 18 (19.4\%) women of mean age $72.0 \pm 8.3$ years. Considering the location of the plaque, $43(46.2 \%)$ patients showed atherosclerosis extending from the proximal to the distal area, but in most of the cases atherosclerosis was dominant in one area. Only 8 patients showed discrepancy between the two researchers. Finally, after a consensus meeting, 31 (33.3\%) had high-apical and 62 (66.7\%) had low-body plaque.

\section{Characteristics of patients with high-apical and low-body plaques}

Table 1 shows that history of hyperlipidemia was significantly more frequent in patients with low-body than high-apical plaques $(p=0.022)$. The CCA-ICA angle was significantly wider in patients with low-body than highapical plaques $\left(167.7 \pm 10.4^{\circ}\right.$ vs. $162.3 \pm 9.8^{\circ}, p=0.019$;
Table 1 Baseline demographic and clinical characteristics of patients with high-apical and low-body plaques

\begin{tabular}{|c|c|c|c|}
\hline Variables & $\begin{array}{l}\text { High-apical type } \\
(n=31)\end{array}$ & $\begin{array}{l}\text { Low-body type } \\
(n=62)\end{array}$ & $P$ value \\
\hline Age, y & $72.7 \pm 6.8$ & $71.7 \pm 9.0$ & 0.588 \\
\hline Male sex & $23(74.2)$ & $52(83.9)$ & 0.265 \\
\hline Hypertension & 25 (80.6) & $48(77.4)$ & 0.721 \\
\hline Diabetes mellitus & $12(38.7)$ & $21(33.9)$ & 0.646 \\
\hline Hyperlipidemia & $15(48.4)$ & $45(72.6)$ & 0.022 \\
\hline Smoking & $17(54.8)$ & $36(58.1)$ & 0.767 \\
\hline History of stroke or TIA & $11(35.5)$ & $15(24.2)$ & 0.253 \\
\hline \multicolumn{4}{|l|}{ Previous medication } \\
\hline Antiplatelet & $12(38.7)$ & $30(48.4)$ & 0.377 \\
\hline Statin & $9(29.0)$ & $25(40.3)$ & 0.287 \\
\hline \multicolumn{4}{|l|}{ Laboratory findings } \\
\hline WBC, per $\mathrm{mm}^{2}$ & $9144.2 \pm 5383.2$ & $8514.7 \pm 2669.0$ & 0.452 \\
\hline Hematocrit & $38.8 \pm 6.2$ & $40.6 \pm 4.9$ & 0.119 \\
\hline Platelet, $\times 10^{3} / \mathrm{mm}^{2}$ & $264.0 \pm 115.2$ & $236.8 \pm 65.8$ & 0.152 \\
\hline Glucose, mg/dL & $124.9 \pm 36.8$ & $137.3 \pm 53.6$ & 0.262 \\
\hline $\begin{array}{l}\text { Glycated hemoglobin } \\
(\mathrm{HbA} 1 \mathrm{c})\end{array}$ & $6.3 \pm 1.1$ & $6.5 \pm 1.4$ & 0.610 \\
\hline Total cholesterol, mg/dL & $159.5 \pm 55.9$ & $170.7 \pm 51.4$ & 0.341 \\
\hline HDL cholesterol, mg/dL & $37.7 \pm 8.8$ & $40.7 \pm 11.4$ & 0.202 \\
\hline Triglyceride, mg/dL & $132.6 \pm 80.1$ & $146.3 \pm 104.4$ & 0.523 \\
\hline LDL cholesterol, mg/dL & $106.4 \pm 41.7$ & $108.8 \pm 39.9$ & 0.785 \\
\hline $\mathrm{BUN}, \mathrm{mg} / \mathrm{dL}$ & $17.0 \pm 6.0$ & $18.6 \pm 7.4$ & 0.303 \\
\hline Creatinine, mg/dL & $0.9 \pm 0.3$ & $1.0 \pm 0.7$ & 0.679 \\
\hline $\mathrm{CRP}, \mathrm{mg} / \mathrm{dL}$ & $1.2 \pm 3.9$ & $0.7 \pm 2.1$ & 0.393 \\
\hline
\end{tabular}

Values are expressed as number (\%), mean \pm standard deviation, or median [interquartile range].

Abbreviations: BUN blood urea nitrogen, $C R P$ C-reactive protein, $H D L$ highdensity lipoprotein, $L D L$ low-density lipoprotein, TIA transient ischemic attack, $W B C$ white blood cell

Table 2). Multivariable analysis showed that, relative to high-apical plaques, wider CCA-ICA angle (OR: 1.061, 95\% CI: $1.010-1.115, p=0.018)$ and narrower ICA-ECA angle (OR: $0.961,95 \% \mathrm{CI}: 0.925-0.999, p=0.043$ ) were independently associated with low-body plaques (Supplementary Table S1).

\section{Carotid geometry and lesion pattern}

Small scattered lesions were more frequently associated with low-body plaques $(54.8 \%$ vs. $32.3 \%, p=0.040)$, whereas large lesions accompanied by additional lesions were more frequently associated with high-apical plaques $(38.7 \%$ vs. $11.3 \%, p=0.002$; Table 2$)$. An analysis of clinical and imaging factors according to lesion pattern and location on DWI found that there was no difference except the prevalence of low-body plaque (Supplementary Table S2 and Supplementary Table S3, respectively). Multivariable analysis comparing the small lesions only 
Table 2 Carotid geometry and lesion patterns among patients with high-apical and low-body plaques

\begin{tabular}{|c|c|c|c|}
\hline & $\begin{array}{l}\text { High-apical type } \\
(n=31)\end{array}$ & $\begin{array}{l}\text { Low-body type } \\
(n=62)\end{array}$ & $P$ value \\
\hline \multicolumn{4}{|l|}{ Carotid geometry } \\
\hline ICA-ECA angle, ${ }^{\circ}$ & $28.4 \pm 14.9$ & $22.8 \pm 10.0$ & 0.067 \\
\hline CCA-ICA angle, ${ }^{\circ}$ & $162.3 \pm 9.8$ & $167.7 \pm 10.4$ & 0.019 \\
\hline CCA-ECA angle, ${ }^{\circ}$ & $168.8 \pm 12.4$ & $169.1 \pm 12.1$ & 0.869 \\
\hline ICA-to-CCA diameter ratio & $0.56 \pm 0.13$ & $0.55 \pm 0.12$ & 0.832 \\
\hline ICA planarity & $17.0 \pm 8.9$ & $18.1 \pm 10.7$ & 0.625 \\
\hline $\begin{array}{l}\text { ICA stenosis severity } \\
\text { (NASCET) }\end{array}$ & $69.2 \pm 11.4$ & $64.6 \pm 13.6$ & 0.105 \\
\hline Kinking of ICA & $2(6.5)$ & $3(4.8)$ & 0.999 \\
\hline Ulceration of plaque & $16(51.6)$ & $35(56.5)$ & 0.658 \\
\hline Carotid web & 0 & 0 & $\mathrm{~N} / \mathrm{A}$ \\
\hline \multicolumn{4}{|l|}{ Lesion pattern on DWI } \\
\hline $\begin{array}{l}\text { Small }(<15 \mathrm{~mm}) \text { single } \\
\text { cortical lesion }\end{array}$ & $2(6.5)$ & $2(3.2)$ & 0.598 \\
\hline $\begin{array}{l}\text { Small }(<15 \mathrm{~mm}) \text { single } \\
\text { subcortical lesion }\end{array}$ & $1(3.2)$ & $4(6.5)$ & 0.662 \\
\hline $\begin{array}{l}\text { Small }(<15 \mathrm{~mm}) \text { multiple } \\
\text { scattered lesions }\end{array}$ & $10(32.3)$ & $34(54.8)$ & 0.040 \\
\hline $\begin{array}{l}\text { Large single cortico- } \\
\text { subcortical lesion }\end{array}$ & $5(16.1)$ & $9(14.5)$ & 0.999 \\
\hline $\begin{array}{l}\text { Large single } \\
\text { subcortical lesion }\end{array}$ & $1(3.2)$ & $6(9.7)$ & 0.418 \\
\hline $\begin{array}{l}\text { Large lesion with } \\
\text { additional lesions }\end{array}$ & $12(38.7)$ & $7(11.3)$ & 0.002 \\
\hline
\end{tabular}

Values are expressed as number (\%) or mean \pm standard deviation.

Abbreviations: CCA common carotid artery, DWI diffusion-weighted imaging, ECA external carotid artery, ICA internal carotid artery, N/A not available, NASC ET North American Symptomatic Carotid Endarterectomy Trial

pattern found that low-body plaque was the only factor independently associated with the small lesions only pattern (OR: 3.106, 95\% CI: 1.105-8.728, $p=0.032$; Table 3).

\section{Discussion}

The present study found that the CCA-ICA angle was wider in patients with low-body than high-apical plaques. These low-body plaques showed a greater association with small scattered lesions and were independently associated with having only small lesions of diameter $<15 \mathrm{~mm}$.
Patients with high-apical plaques had a narrower CCAICA angle and were more likely to have large ischemic lesions.

In agreement with previous findings [7], the present study found that a history of hyperlipidemia was associated with low-body plaques. Hyperlipidemia, however, acts systemically, making its association with the specific location of atherosclerosis unclear. Local factors such as vascular geometry may influence the site of atherosclerosis development. A study of the computational fluid dynamics of the carotid artery found that the bifurcation angle was significantly negatively correlated with WSS in the inner and outer walls of the ICA, which may have been due to a loss of energy [21]. A decrease in the CCA-ICA angle may be associated with a more rapid decrease in WSS in the inner than in the outer wall of the ICA [21]. These may explain our result showing that a decreased CCA-ICA angle was independently associated with the presence of high-apical plaques. Of our 31 patients with high-apical plaques, 25 had plaques located in the inner curvature and a more rapid decrease in WSS. Furthermore, a second angle is present in patients with a decreased CCA-ICA angle, leading to low WSS in the inner curvature that is prone to atherosclerosis development [22].

Our results also showed that the lesion patterns on DWI in acute ischemic stroke patients with symptomatic pICA disease were associated with plaque location, but not with the geometry of the ICA or the presence of ulcer. Small scattered lesions were associated with low-body plaques of the ICA, whereas the presence of a large lesion with additional lesions was associated with high-apical plaques. Dichotomization of lesion patterns according to the presence or absence of a large lesion resulted in lowbody plaques being independently associated with the small lesion-only pattern. In high-apical plaques, the bulb is proximal to the stenotic portion with a back flow causing fluid stagnation and thrombus formation, such as in the appendage of the left atrium [23, 24]. This may cause a large thrombus inside the bulb area, resulting in a largesized infarction [25]. By contrast, low-body plaques increase the flow velocity at the bulb area. The high speed flow may induce shear dependent platelet activation and

Table 3 Multivariable analysis of factors associated with the small lesion-only type

\begin{tabular}{|c|c|c|c|}
\hline & $\begin{array}{l}\text { Model 1, unadjusted } \\
\text { Odds ratio }(95 \% \mathrm{Cl})\end{array}$ & $\begin{array}{l}\text { Model 2, } \\
{ }^{a} \text { Odds ratio }(95 \% \mathrm{Cl})\end{array}$ & $\begin{array}{l}\text { Model } 3 \text {, } \\
\text { bOdds ratio }(95 \% \mathrm{Cl})\end{array}$ \\
\hline$\overline{\text { ICA-ECA angle, }}{ }^{\circ}$ & $0.998(0.965-1.032)$ & 0.999 (0.959-1.040) & 0.999 (0.960-1.042) \\
\hline CCA-ICA angle, ${ }^{\circ}$ & 0.978 (0.940-1.018) & $0.970(0.927-1.015)$ & $0.970(0.927-1.016)$ \\
\hline CCA-ECA angle, ${ }^{\circ}$ & $1.021(0.986-1.057)$ & $1.029(0.987-1.073)$ & $1.027(0.984-1.072)$ \\
\hline Low-body plaque & $2.571(1.041-6.087)^{*}$ & $3.058(1.107-8.449)^{*}$ & $3.106(1.105-8.728)^{*}$ \\
\hline
\end{tabular}

${ }^{*} p<0.05$

${ }^{a}$ Adjusted for hypertension, low-density lipoprotein cholesterol, and white blood cell count.

${ }^{\mathrm{b}}$ Adjusted for age, male sex, hypertension, low-density lipoprotein cholesterol, and white blood cell count.

Abbreviations: CCA common carotid artery, Cl confidence interval, ECA external carotid artery, ICA internal carotid artery 


\section{A}
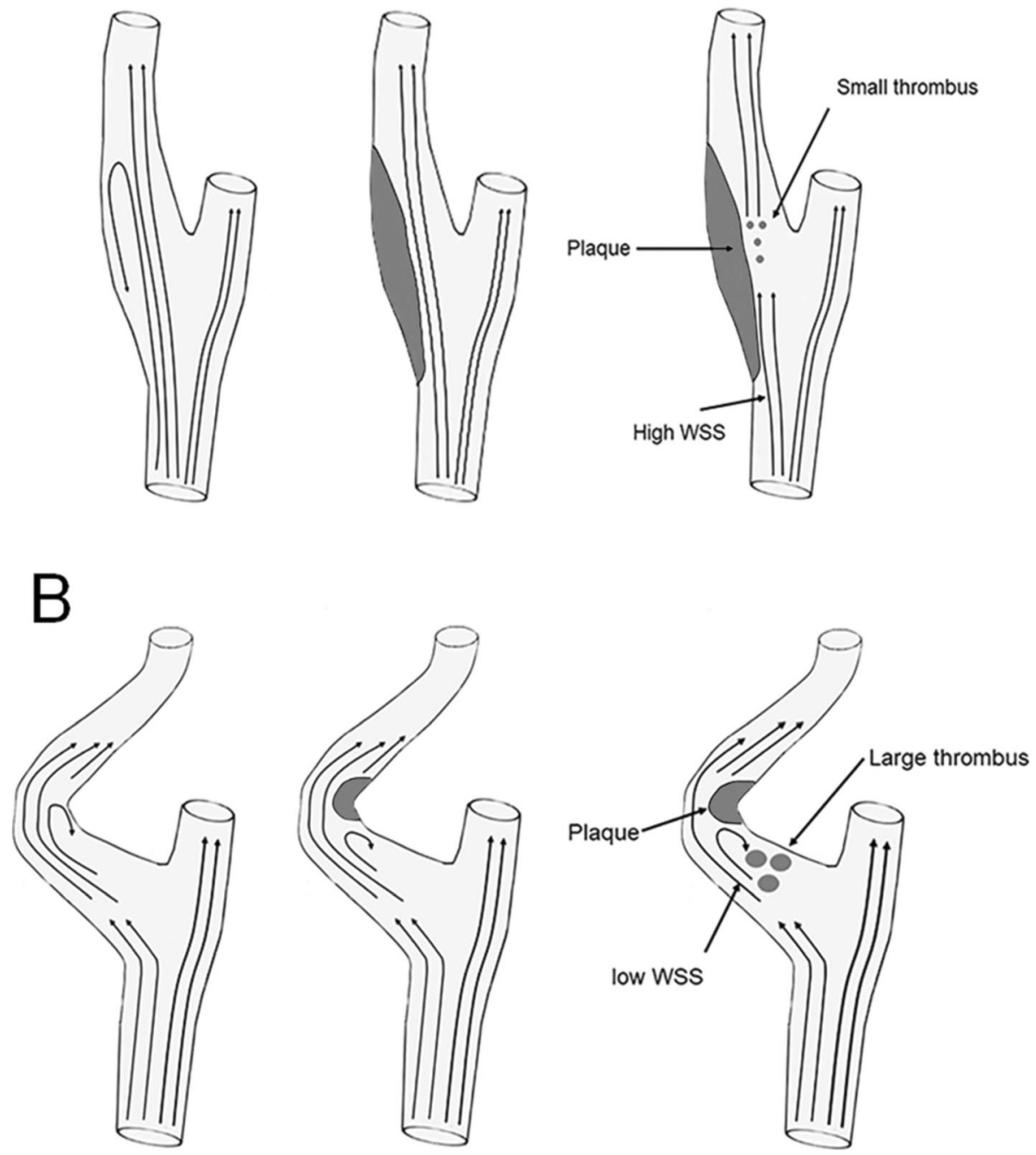

Fig. 1 Schematic drawing of plaque and thrombus formation in the carotid artery

generate multiple small thrombi, resulting in small scattered lesions (Fig. 1) [26].

The present study had several limitations. First, its retrospective nature may have caused a selection bias. Second, the number of patients was small, under-powering some of our results, especially the lesion patterns. Third, geometry was analyzed based on two-dimensional anteroposterior images of three-dimensionally reconstructed MRA images. Though three-dimensional analysis of the vascular geometry might strengthen our results, two-dimensional analysis is more practical. Fourth, the present study did not analyze the state of intracerebral hemodynamics, the activation of the collateral circulation, or the presence of microembolic signals. Finally, this study did not pathologically assess the composition and vulnerability of the plaques or the size and composition of the embolus resulting from each stroke mechanism. Despite these limitations, our results suggest the importance of vascular geometry in the development of acute stroke in patients with symptomatic pICA disease.

\section{Conclusion}

The CCA-ICA angle may be a factor determining the location of atherosclerotic plaques of the carotid artery, probably altering hemodynamics. Differences in the locations of carotid plaques may explain, at least in part, inter-individual differences in the location of lesions in acute ischemic stroke in patients with symptomatic pICA disease. 


\section{Supplementary information}

Supplementary information accompanies this paper at https://doi.org/10. 1186/s12883-020-01868-0.

\section{Additional file 1}

Additional file 2: Table S1. Multivariable analysis of factors associated with low-body plaques. Table S2. Association independent factors with lesion pattern on diffusion-weighted imaging. Table S3. Association independent factors with lesion location including cortical, subcortical, and cortico-subcortical lesions.

\section{Abbreviations}

WSS: Wall shear stress; DWI: Diffusion-weighted imaging; TOAST: Trial of Org 10,172 in Acute Stroke Treatment; pICA: proximal internal carotid artery; MCA: Middle cerebral artery; ACA: Anterior cerebral artery; MRA: Magnetic resonance angiography; CCA: Common carotid artery; ECA: External carotid artery; NASCET: North American Symptomatic Carotid Endarterectomy Trial: ORs: Odds ratios; Cls: Confidence intervals

\section{Acknowledgments}

Not applicable.

\section{Authors' contributions}

Research conception and design: H.G.W., T.J.S., S.H.H., D.I.C., and B.J.K. Data acquisition: H.G.W., S.H.H., E.J.K., D.I.C., and B.J.K. Data analysis and interpretation: H.G.W., T.J.S., S.H.H., E.J.K., D.I.C., and B.J.K. Statistical analysis: H.G.W., T.J.S., and B.J.K. Drafting of the manuscript: H.G.W., T.J.S., S.H.H., and B.J.K. Critical revision of the manuscript: H.G.W., T.J.S., S.H.H., E.J.K., D.I.C., and B.J.K. All authors have approved the final manuscript.

\section{Funding}

This research was supported by a grant of the Korea Health Technology R\&D Project through the Korea Health Industry Development Institute (KHIDI), funded by the Ministry of Health \& Welfare, Republic of Korea (grant number: HI18C2383). However, the funder had no role in the study design, data collection and analysis, decision to publish, or preparation of the manuscript.

\section{Availability of data and materials}

Our dataset was prospectively collected registry for stroke patients in our hospital. The datasets used and/or analyzed during the current study are available from the corresponding author on reasonable request. Public access to the datasets is closed and administrative permission was needed to access and use our datasets.

\section{Ethics approval and consent to participate}

The study was approved by the institutional review board of Kyung Hee University Hospital, which waived the need for informed consent because of its retrospective nature.

\section{Consent for publication}

Not applicable.

\section{Competing interests}

The authors declare that they have no competing interests.

\section{Author details}

'Departments of Neurology, Kyung Hee University College of Medicine, Seoul, South Korea. ${ }^{2}$ Departments of Radiology, Kyung Hee University College of Medicine, Seoul, South Korea. ${ }^{3}$ Department of Neurology, Seoul Hospital Ewha Womans University College of Medicine, Seoul, South Korea. ${ }^{4}$ Department of Neurology, Asan Medical Center, University of Ulsan, Song-Pa, PO Box 145, Seoul 138-600, South Korea.

Received: 29 April 2020 Accepted: 22 July 2020

Published online: 30 July 2020

\section{References}

1. Kim JS, Nah HW, Park SM, Kim SK, Cho KH, Lee J, et al. Risk factors and stroke mechanisms in atherosclerotic stroke: intracranial compared with extracranial and anterior compared with posterior circulation disease. Stroke. 2012;43(12):3313-8. https://doi.org/10.1161/STROKEAHA.112.658500.

2. Homburg PJ, Rozie S, van Gils MJ, Jansen T, de Weert TT, Dippel DW, et al. Atherosclerotic plaque ulceration in the symptomatic internal carotid artery is associated with nonlacunar ischemic stroke. Stroke. 2010;41(6):1151-6. https://doi.org/10.1161/STROKEAHA.109.576256.

3. Rothwell PM, Gibson R, Warlow CP. Interrelation between plaque surface morphology and degree of stenosis on carotid angiograms and the risk of ischemic stroke in patients with symptomatic carotid stenosis. On behalf of the European carotid surgery Trialists' collaborative group. Stroke. 2000; 31(3):615-21. https://doi.org/10.1161/01.str.31.3.615.

4. Cicha I, Worner A, Urschel K, Beronov K, Goppelt-Struebe M, Verhoeven E, et al. Carotid plaque vulnerability: a positive feedback between hemodynamic and biochemical mechanisms. Stroke. 2011;42(12):3502-10. https://doi.org/10.1161/STROKEAHA.111.627265.

5. Oshida S, Mori F, Sasaki M, Sato Y, Kobayshi M, Yoshida K, et al. Wall shear stress and $\mathrm{T} 1$ contrast ratio are associated with embolic signals during carotid exposure in endarterectomy. Stroke. 2018;49(9):2061-6. https://doi. org/10.1161/STROKEAHA.118.022322.

6. Younis HF, Kaazempur-Mofrad MR, Chan RC, Isasi AG, Hinton DP, Chau AH, et al. Hemodynamics and wall mechanics in human carotid bifurcation and its consequences for atherogenesis: investigation of inter-individual variation. Biomech Model Mechanobiol. 2004;3(1):17-32. https://doi.org/10. 1007/s10237-004-0046-7.

7. Park ST, Kim JK, Yoon KH, Park SO, Park SW, Kim JS, et al. Atherosclerotic carotid stenoses of apical versus body lesions in high-risk carotid stenting patients. AJNR Am J Neuroradiol. 2010;31(6):1106-12. https://doi.org/10. 3174/ajnr.A2000

8. Phan TG, Beare RJ, Jolley D, Das G, Ren M, Wong K, et al. Carotid artery anatomy and geometry as risk factors for carotid atherosclerotic disease. Stroke. 2012;43(6):1596-601. https://doi.org/10.1161/STROKEAHA.111.645499.

9. Kamiya A, Togawa T. Adaptive regulation of wall shear stress to flow change in the canine carotid artery. Am J Phys. 1980;239(1):H14-21. https://doi.org/10.1152/ajpheart.1980.239.1.H14.

10. Adams HP Jr, Bendixen BH, Kappelle LJ, Biller J, Love BB, Gordon DL, et al. Classification of subtype of acute ischemic stroke. Definitions for use in a multicenter clinical trial. TOAST. Trial of org 10172 in acute stroke treatment. Stroke. 1993;24(1):35-41.

11. North American Symptomatic Carotid Endarterectomy Trial C, HJM B, Taylor DW, Haynes RB, Sackett DL, Peerless SJ, et al. Beneficial effect of carotid endarterectomy in symptomatic patients with high-grade carotid stenosis. N Engl J Med. 1991;325(7):445-53. https://doi.org/10.1056/NEJM199108153250701.

12. Fox AJ, Eliasziw M, Rothwell PM, Schmidt MH, Warlow CP, Barnett HJ. Identification, prognosis, and management of patients with carotid artery near occlusion. AJNR Am J Neuroradiol. 2005:26(8):2086-94.

13. National Cholesterol Education Program Expert Panel on Detection $E_{\text {, }}$ Treatment of High Blood Cholesterol in A. Third report of the National Cholesterol Education Program (NCEP) expert panel on detection, evaluation, and treatment of high blood cholesterol in adults (adult treatment panel III) final report. Circulation. 2002;106(25):3143-421.

14. Kang DW, Chalela JA, Ezzeddine MA, Warach S. Association of ischemic lesion patterns on early diffusion-weighted imaging with TOAST stroke subtypes. Arch Neurol. 2003:60(12):1730-4. https://doi.org/10.1001/archneur.60.12.1730.

15. Kim BJ, Kim HJ, Do Y, Lee JH, Park KY, Cha JK, et al. The impact of prior antithrombotic status on cerebral infarction in patients with atrial fibrillation. J Stroke Cerebrovasc Dis. 2014;23(8):2054-9. https://doi.org/10.1016/j. jstrokecerebrovasdis.2014.03.011.

16. Tatu L, Moulin T, Bogousslavsky J, Duvernoy H. Arterial territories of the human brain: cerebral hemispheres. Neurology. 1998;50(6):1699-708.

17. Thomas JB, Antiga L, Che SL, Milner JS, Steinman DA, Spence JD, et al. Variation in the carotid bifurcation geometry of young versus older adults: implications for geometric risk of atherosclerosis. Stroke. 2005;36(11):2450-6. https://doi.org/10.1161/01.STR.0000185679.62634.0a.

18. Etesami M, Hoi Y, Steinman DA, Gujar SK, Nidecker AE, Astor BC, et al. Comparison of carotid plaque ulcer detection using contrast-enhanced and time-of-flight MRA techniques. AJNR Am J Neuroradiol. 2013;34(1):177-84. https://doi.org/10.3174/ajnr.A3132.

19. Lantos JE, Chazen JL, Gupta A. Carotid web: appearance at MR angiography AJNR Am J Neuroradiol. 2016;37(1):E5-6. https://doi.org/10.3174/ajnr.A4598.

20. Illuminati G, Calio FG, Papaspyropoulos V, Montesano G, D'Urso A Revascularization of the internal carotid artery for isolated, stenotic, and 
symptomatic kinking. Arch Surg. 2003;138(2):192-7. https://doi.org/10.1001/ archsurg.138.2.192.

21. Saho T, Onishi H. Evaluation of the impact of carotid artery bifurcation angle on hemodynamics by use of computational fluid dynamics: a simulation and volunteer study. Radiol Phys Technol. 2016;9(2):277-85. https://doi.org/10.1007/s12194-016-0360-7.

22. Wahle A, Lopez JJ, Olszewski ME, Vigmostad SC, Chandran KB, Rossen JD, et al. Plaque development, vessel curvature, and wall shear stress in coronary arteries assessed by X-ray angiography and intravascular ultrasound. Med Image Anal. 2006;10(4):615-31. https://doi.org/10.1016/j. media.2006.03.002

23. Bosi GM, Cook A, Rai R, Menezes LJ, Schievano S, Torii R, et al. Computational fluid dynamic analysis of the left atrial appendage to predict thrombosis risk. Front Cardiovasc Med. 2018;5:34. https://doi.org/10.3389/fcrm.2018.00034.

24. Beigel R, Wunderlich NC, Ho SY, Arsanjani R, Siegel RJ. The left atrial appendage: anatomy, function, and noninvasive evaluation. JACC Cardiovasc Imaging. 2014;7(12):1251-65. https://doi.org/10.1016/j.jcmg.2014.08.009.

25. Puetz V, Dzialowski I, Hill MD, Subramaniam S, Sylaja PN, Krol A, et al. Intracranial thrombus extent predicts clinical outcome, final infarct size and hemorrhagic transformation in ischemic stroke: the clot burden score. Int J Stroke. 2008;3(4):230-6. https://doi.org/10.1111/j.1747-4949.2008.00221.x.

26. Fox SC, Sasae R, Janson S, May JA, Heptinstall S. Quantitation of platelet aggregation and microaggregate formation in whole blood by flow cytometry. Platelets. 2004;15(2):85-93. https://doi.org/10.1080/ 09537100310001645979

\section{Publisher's Note}

Springer Nature remains neutral with regard to jurisdictional claims in published maps and institutional affiliations.

Ready to submit your research? Choose BMC and benefit from:

- fast, convenient online submission

- thorough peer review by experienced researchers in your field

- rapid publication on acceptance

- support for research data, including large and complex data types

- gold Open Access which fosters wider collaboration and increased citations

- maximum visibility for your research: over $100 \mathrm{M}$ website views per year

At $\mathrm{BMC}$, research is always in progress.

Learn more biomedcentral.com/submissions 